\title{
Intentional Nonadherence as a Means to Exert Control
}

\author{
Caroline Huyard', Luc Derijks², Harm Haak², \\ and Louis Lieverse ${ }^{2}$
}

\begin{abstract}
Medication adherence is a major issue for patients with a chronic illness, who sometimes rationally choose temporary nonadherence. This study aims at better understanding intentional nonadherence and especially why it seems to fluctuate over time. It is based on $\mathbf{4 8}$ semi-structured interviews conducted in a hospital in the Netherlands with patients who had been prescribed a medication for a chronic disease for at least I year, and who had either type 2 diabetes, hypertension, Parkinson's disease, inflammatory bowel disease, or chronic myeloid leukemia. The analysis uses a simplified version of the failure modes and effects analysis (FMEA) method. Intentional nonadherence appeared to be the result of the respondents' desire (a) to exert control over the treatment and its effects on their body, and (b) to control the hold of the treatment on their daily life. This result provides a rationale for the fluctuation of intentional nonadherence behavior.
\end{abstract}

\section{Keywords}

adherence, compliance, nonadherence, noncompliance, chronic, illness and disease, experiences, motivation, power, empowerment, self-care, self, Western Europe, Europe, Europeans, interviews, research strategies, coding, qualitative, failure modes and effects analysis (FMEA).

\section{Introduction}

Nonadherence, or poor adherence, is one of the major contemporary challenges in the field of health. Adherence can be defined as "the extent to which a person's behavior - taking medication, following a diet, and/or executing lifestyle changes, corresponds with agreed recommendations from a healthcare provider" (World Health Organization, 2003, p.4). According to the World Health Organization (2003), nonadherence affects $50 \%$ of chronic patients in developed countries and leads to poor health outcomes and increased health costs, so that increasing the effectiveness of adherence interventions may have a greater impact on the health of the population than any improvement in specific medical treatments. Understanding the reasons for nonadherence is therefore essential.

As chronic diseases were expanding in the early 1980 s, some authors have suggested that it could be useful to distinguish between intentional and unintentional adherence (Cooper, Love, \& Raffoul, 1982) arguing that if nonadherence was intentional, efforts aimed at reducing forgetting to take the medications would have little chance to help the patients. In line with this insight, many studies have tried to evidence what factors could lead patients to intentional nonadherence and what factors could lead them to unintentional nonadherence. Various definitions of intentional nonadherence were crafted for this purpose, ranging from the rather neutral views that intentional nonadherence involves deliberate decisions to adjust medication use (Laba, Brien, \& Jan, 2012) and occurs when patients actively choose not to follow treatment recommendations (Daleboudt, Broadbent, McQueen, \& Kaptein, 2010) or discontinue, skip or alter the dose of medication they had been prescribed (Iihara et al., 2014) to more hypothesis-ladden views, such as the ones that nonadherence occurs when patients miss or alter doses to suit their needs (Wroe, 2002) and it is associated with motivation and patients' beliefs about taking medications (Clifford, Barber, \& Horne, 2008).

There is now a large body of studies that investigated why patients would rationally choose nonadherence. Some major factors have been identified. Most studies

\footnotetext{
'Universite De Lille, CNRS, UMR 8026, France

${ }^{2}$ Máxima Medisch Centrum, Eindhoven, Noord-Brabant, The Netherlands

\section{Corresponding author:}

Caroline Huyard, Univ. Lille, CNRS, UMR 8026 - CERAPS - Centre d'Études et de Recherches Administratives Politiques et Sociales, F59000, Lille, France.

Email: caroline.huyard@univ-lille2.fr
} 
agree that medications' side effects strongly contribute to patients' intentional nonadherence (Khan, Shah, \& Hameed, 2014; Laba, Brien, Fransen, \& Jan, 2013; Laba, Lehnbom, Brien, \& Jan, 2015; Noens et al., 2014; Thunander Sundbom \& Bingefors, 2012). A large number of studies have also highlighted the role of patients' beliefs about the benefits and the necessity of their treatment in their decision not to take it as prescribed (Chambers et al., 2011; Iihara et al., 2004; Laba et al., 2012; Wileman et al., 2011), and in line with this, studies showed that patients' judgments on the absence of symptoms (Ulrik et al., 2006), their concern beliefs (de Vries et al., 2014), perceived risks (Laba et al., 2012; Ulrik et al., 2006; Wileman et al., 2011), or their perception that the treatment would be ineffective (Laba et al., 2015) foster nonadherence behaviors. This is in line with many qualitative studies pointing to patients' broader concerns about medications as potentially harmful products and their preference to take

Recently, some studies have focused on the temporal dimension of adherence and intentional nonadherence behavior. Several studies point out that intentional nonadherence is usually a temporary and reversible phenomenon and not a complete discontinuation (Murdoch, Salter, Poland, \& Cross, 2015; Laba et al., 2015; Wroe \& Thomas, 2003). Patients report that they sometimes "take a break" (Norton et al., 2010) This is important, because the factors and reasons for intentional nonadherence listed above do not adequately account for these fluctuations. Existing studies indeed investigated intentional nonadherence as the rational decision to take or not to take the treatment (Herrera, Moncada, \& Defey, 2016; Wroe, 2002) and considered some parameters that could be involved in weighing the decision, such as information about the disease, about the treatment, and about the benefits and the expected risks; beliefs based on personal experience and personal values; and some constraints, especially economic and practical ones. But for nonadherence to be temporary, this would imply that the information, beliefs, and constraints fluctuate over time and result in similar fluctuations in treatment adherence behavior. This may happen over a time span of several years, but does not seem plausible over the much shorter time span of a few weeks or days evidenced in the studies. So why does intentional nonadherence fluctuate over time?

In this study, we aimed to better understand the reasons for fluctuations in intentional nonadherence behaviors. For this purpose, we draw on a classical idea in the sociology of health, namely, that chronic patients have to perform a certain amount of work (Corbin \& Strauss, 1988; Senteio \& Veinot, 2014). A key dimension of treatment behavior in chronic diseases lays in its repetitive and active nature over long periods of time. Indeed, adherence in chronic diseases means that the patients succeed in performing medication taking, disease monitoring, or carrying on an appropriate lifestyle every single day for decades. In particular, medication adherence behavior is the concrete task of as little as possible (Pound et al., 2005). Last, many studies agree on the role of health care payment systems: When patients must contribute significantly to the cost of their treatment, they tend to be less adherent (Laba et al., 2013; Laba et al., 2015; Wileman et al., 2011). Other factors have also been identified, such as treatment schedule (Laba et al., 2012; Laba et al., 2013; Wileman et al., 2011), patient-practitioner relationships (Laba et al., 2012), patients' behavioral skills regarding illness and treatment (Norton et al., 2010), age, and selfefficacy (Ostini \& Kairuz, 2014). Some reviews ruled out two potential explanatory factors, namely, a linear relationship between intentional nonadherence and health literacy (Ostini \& Kairuz, 2014) and psychosocial predictors such as coping styles, social influences and social support, personality traits, and psychosocial wellbeing (Zwikker, van den Bemt, Vriezekolk, van den Ende, \& van Dulmen, 2014).

taking the right amount of the right medication at the right time and in the right circumstances. In this perspective, adherence is similar to a prescribed work for which the worker has to use particular tools, at particular stages, to perform a task in a particular way to reach a particular goal. The reasons why workers do not perform their tasks as prescribed can refer to a variety of reasons that are hypothesized not to be only a matter of information, knowledge, or belief. Thus, what must be understood is why the patients sometimes perform treatment adherence as prescribed and sometimes decide to perform this task in their own way.

\section{Method}

This study is based on 48 semi-structured interviews conducted in a public hospital in the Netherlands in 2014 with patients suffering from type 2 diabetes, hypertension, Parkinson's disease, inflammatory bowel disease, or chronic myeloid leukemia who had been prescribed a medication for a chronic disease for at least 1 year. The conditions were selected to have a sample of contrasting situations with respect to treatment and medication practice and to factors that influence them. Some often involve doctor-prescribed lifestyle changes in addition to medication taking (diabetes and hypertension), others often involve patient-chosen lifestyle changes (inflammatory bowel disease), others involve none (Parkinson's disease and chronic myeloid leukemia), and it is known that whether a treatment regimen is limited or pervasive is important (DiMatteo, 2004). Some conditions react to treatment in a way that cannot be monitored by the patients themselves (chronic myeloid leukemia), others can be monitored by the patients themselves on the basis of their own bodily perceptions (Parkinson's disease, inflammatory bowel disease), and others can be monitored by the patients themselves on the basis of their own bodily perceptions or of specific devices (diabetes and hypertension). Some conditions have acute phases (inflammatory bowel 
disease) or an acute onset (chronic myeloid leukemia, sometimes hypertension), and it is known that both the

The Institutional Review Board/Independent Ethics Committee of the Máxima Medical Center declared that this study did not have to be reviewed by a medical ethics board according to the Dutch Medical Research Involving Human Subjects Act (WMO). Each interviewee's informed written consent was recorded. Outpatients were contacted by a research nurse or a physician. They were selected according to a simple systematic procedure: The patients were asked some time prior to a scheduled appointment if they would accept an interview in addition to their medical appointment. The first patients who did accept to participate were included. No patient declined to take part. The interview guide addressed the patient's medical history (asking, for instance, "Could you describe how your illness began?") and medical treatment (e.g., "What do you personally expect from this treatment?"), how the medical treatment was integrated into daily life (e.g., "Have you found out particular tricks to help you deal with your illness? What tricks? Did you mention them to your doctor?"), patient's personal experience of the illness (e.g., "Do you sometimes feel weary/discouraged/angry about your treatment? What are the consequences of these feelings?"), patient's knowledge and needs about the disease (e.g., "Where do you find the information you need about your illness and your treatment?"), and illness and treatment disclosure (e.g., "Do your relatives and your friends know about your illness? And about your treatment? How have they been informed about it? How did they react?"). The interviews were recorded and fully transcribed.

The interviewees have a range of backgrounds and family situations that make the interviews diverse enough, while these sociodemographic characteristics are not different from those of the patients' population. Their sociodemographic characteristics are given in Table 1.

The research was informed by the method of failure modes and effects analysis (FMEA; Franklin, Shebl, \& Barber, 2012). This method is used in engineering and more specifically quality engineering, including quality engineering with respect to safety hazards (Lux, Mawo De Bikond, Etienne, \& Quillerou-Grivot, 2016) or with respect to human mistakes (Hertig, Hultgren, Parks, \& Rondinelli, 2016). It is used for identifying all possible failures in a design, a manufacturing or assembly process, or a product or service. It can be used for different purposes, including analyzing failures of an existing process. It addresses a particular function in a process, a product, or a service and aims to identify potential failure modes, potential effects of the failure, potential causes of failure and their occurrence rate, the current process controls and their detection rate, recommended actions to lower occurrence or severity of failures, and the results of these actions. For instance, FMEA can be used to improve safety in a radiation modes of perception of the illness and its critical phases play a role in medication practices (Conrad, 1985).

oncology unit (Ford et al., 2009), where a safe and effective radiotherapy treatment has to treat the correct tissue in the correct patient with the correct dose. Used in a prospective way, FMEA starts with describing the work flow in the unit from the patient's point of view

Table I. Sociodemographic Characteristics of the Interviewees.

\begin{tabular}{lc}
\hline Parameter $\quad$ Value & $\begin{array}{c}\text { Number of } \\
\text { Interviewees }\end{array}$ \\
\hline Sex & 26 \\
Men & 22 \\
Women & \\
Disease & 16 \\
Type 2 diabetes & 6 \\
Types 2 diabetes + hypertension & 8 \\
Hypertension & 11 \\
Inflammatory bowel disease & 5 \\
Chronic myeloid leukemia & 2 \\
Parkinson's disease & \\
Age, years & 21 \\
Above 66 & 17 \\
50-65 & 7 \\
30-49 & 3 \\
Less than 30 & \\
Personal life & 33 \\
Married & 5 \\
Cohabiting & 4 \\
Single & 3 \\
Divorced & 3 \\
Widowed & \\
Education & 22 \\
Primary education & 17 \\
Secondary education & \\
Higher education & \\
\hline & \\
\hline
\end{tabular}

and recording each event that happens to that patient or that patient's medical record. This first part of the analysis helps better visualize what should happen in the unit. It allows for description of subprocesses and identification of possible failures in these processes. On this basis, it is possible to score the severity, frequency, or detectability of failures, and to identify improvements that are feasible and effective. This second part of the analysis highlights what could happen and should be prevented.

A key characteristic of this method is thus its focus on the discrepancy between what is prescribed and how and why things could be different from the prescription and go awry. It is very well suited to the analysis of work flows, and this is precisely how we chose to understand and analyze nonadherence. What has been prescribed is for the patient to take the right amount of the right medication prescribed by the medical professional at the right time. What can happen and have negative consequences is any departure from this pattern of tasks. We focused on intentional departures and 
intentional nonadherence, that is, when patients actively choose not to follow treatment recommendations (Daleboudt et al., 2010). FMEA then allows a rigorous and complete understanding of the tasks patients have to perform when taking their medication and of why they sometimes rationally choose to act differently. We would suggest that this makes FMEA patient-centered.

We adapted and used FMEA in a very simplified and retrospective way, as follows: First, all the instances of intentional nonadherence reported in the interviews were identified (i.e., each instance of an actual or potential intentional departure from the prescription, either regarding the medication itself, the amount of the medication, the time when it was taken, or the way to take it); second, these instances were coded and sorted out according to the reason for nonadherence; and third, the labels were blind cross-checked by a second researcher, and differences were discussed until agreement was reached on the final coding. Table 2 illustrates the result of this procedure for two instances.

\section{Results}

Among the 48 interviews, eight contained no instance of nonadherent behavior at all, 21 interviews contained at least one instance of intentional nonadherent behavior, and 28 interviews contained at least one instance of unintentional nonadherent behavior (10 interviews contained both instances of intentional and unintentional nonadherent behavior, and are therefore counted in both groups). In the 21 interviews containing instances of intentional nonadherence, there was a total of 30 such instances (this includes instances of a strong temptation of nonadherence, even if there was no actual nonadherence behavior, because the explanations given by the respondents were interesting).

The analysis of the interviews showed that intentional nonadherence behavior had two main causes:

- The desire of the respondents to exert personal control over the treatment and its effects on their body, especially to avoid side effects, but also to assess the treatment's effectiveness, or to adapt the doses or the schedule to their case (19 instances in 12 interviews).

- The desire of the respondents to control the hold of the treatment on their life, their time, and their activities (11 instances in 10 interviews with only one respondent in both groups).

\section{Patients' Desire to Exert Personal Control Over the Treatment and its Effects on Their Body}

In accordance with the results of previous studies, side effects were often reported by the respondents as the trigger for temporarily modifying or interrupting their treatment. However, it was never merely to remove an unpleasant effect of the treatment. The respondents' concerns were wider and deeper, relating to the need to exert personal control over the treatment and its effects on their body.

Faced with possible side effects, the respondents explained that they first needed to assess whether their complaints were actually related to their treatment. For this purpose, they performed an experiment. They interrupted the treatment to see whether this resulted in a removal of the complaints, as reported by a 63 -year-old woman who has had hypertension for more than 10 years:

Eh ... For a long time, it was fine with those medications, but now, I happen to have some problems with micardis [one of the prescribed medications], I think. Because, on the leaflet, it says that throat complaints can appear. And according to the doctor, it is very infrequent. But, he said, it might be possible. And actually I tried it this week. I have stopped the medication for one week ... Yes, and I should not do that, because then "psssst" the [tension] values go up. But I'm in a choir, and I can in fact hardly sing, and I find it a real pity. And there's something with temperature; when I change rooms, it completely blocks my throat. And I never had that before. So, I guess that it has to do with the medication. Yes.

Similarly, the respondents reported that they modify their treatment to be able to control when side effects would occur. This describes what this 47-year-old woman who has had chronic myeloid leukemia for 7 years does:

Yes, I have sometimes spent one day without taking it. . . . When we go out for dinner and I have eaten so much, I know that I won't have a good night's rest. I've experienced it a couple of times, and then I thought that it was because of the medication, so I thought, I'm not taking it today. But just once, then (laughs).

This line of reasoning helps in understanding why intentional nonadherent behaviors may be temporary and fluctuating. When personal circumstances make the burden of side effects heavier, patients may try to contain them and thus be deliberately nonadherent. On the contrary, when they can withstand the side effects, they may be more adherent.

In the absence of side effects, some respondents explained that they remained cautious because they consider medications as potentially harmful. They try to keep the dose they take as low as possible, as reported by this 68 -year-old man who has had Crohn's disease for 34 years:

Yes, it was about my question: what does the medication do to my body after nearly 30 years of use? And so he (the doctor) said it himself. He had the idea: now we may perhaps reduce it a bit. See what happens. And I must say, a couple of years ago, I did that too; I did that on my own initiative. At least, I had told him: now, I want to reduce it by half. At that time, I had four pills to take, and I reduced from four to two. And after half a year, it became more 
difficult to empty my bowel. . . . And then, I simply decided to take four again on my own initiative. So ... And of course I told him that when we met on the next appointment. That's how I had done that. So.

Table 2. Outcome of the FMEA Procedure for Two Instances of Nonadherence.

\begin{tabular}{|c|c|c|}
\hline Prescribed Behavior & Actual Behavior & $\begin{array}{l}\text { Reason for the Actual Behavior: } \\
\text { Final Coding }\end{array}$ \\
\hline $\begin{array}{l}\text { To inject insulin following a } \\
\text { particular schedule }\end{array}$ & $\begin{array}{l}\text { The only problem is the [insulin] injections. That's } \\
\text { really hard for me. Yes, phhhh ... And at one point I } \\
\text { had enough to inject } 4 \text { times a day. But yes, there is } \\
\text { no alternative. } \\
\text { Q:And what do you do? } \\
\text { Well nothing really, I simply do it and I complain a } \\
\text { bit and I talk a bit with the diabetes nurse. And } \\
\text { then they'll come back with a different solution. A } \\
\text { pump or something. Or I search one more time on } \\
\text { the Internet. And then we gently start doing the } \\
\text { injections again. And we try to keep going. }\end{array}$ & Burden control \\
\hline $\begin{array}{l}\text { To inject insulin following a } \\
\text { particular schedule }\end{array}$ & $\begin{array}{l}\text { My blood sugar was always low, not too low, but it } \\
\text { was always low. So last week, I thought that I would } \\
\text { reduce them myself. The injections. Because I had } \\
\text { seen [the doctor] the week before and he had said, } \\
\text { well it's perfect. I said yes, but I think it is not } \\
\text { enough, the blood sugar is too low. So l've decided } \\
\text { to cut down myself, and he was very satisfied. } \\
\text { Q: But you had decided it on your own? } \\
\text { I have done that on my own for one week. } \\
\text { Adapting the quantity [of insulin]. }\end{array}$ & Treatment control \\
\hline
\end{tabular}

The desire to assess the effects of the treatment is not limited to identification or to the prevention of side effects. This concern is only the most visible part of the assessment and adjustment practices of the respondents. They also want to assess their treatment's effectiveness and sometimes do so by assessing the results of their medical examinations against their past adherence behavior. This is the case with a 52-year-old man who has had type 2 diabetes for 22 years and who reported that he had unintentionally interrupted his treatment for a few days:

And in fact, it (the blood glucose level) was not sky-high at all. And so I thought something like: hey, when I don't take the medication, the values are not very different from what they are when I take it. And then, I acted in a very rigorous manner, eh . . . differently, sort of: I didn't take the medication, but I also almost hardly ate. In the long run, I knew that this was not good. And then, my values were even better than they had been with the medication. And from that moment, yes, I lost confidence in the treatment.

These assessments and the conclusions that the patients draw from them thus offer a better understanding of the nature of temporary intentional nonadherence. Indeed, if the results of medical examinations are satisfactory, the patients are encouraged to carry on their treatment behavior. Conversely, if the medical examinations deliver disappointing results, the patients will be more prone to modify their behavior. This is what happened with this 67-year-old man who has had type 2 diabetes for 50 years:

When you start changing this and that, it's fine, but then, you notice, oh God, it's not so good. And then at some point, you notice that you have more headaches, or that you don't see so well, and then you check your blood sugar, and you see that it is too high again. Or you experiment a bit with the insulin. No, I don't do that anymore.

Some intentionally nonadherent treatment behaviors thus result from the desire to exert a form of personal control over the treatment and its positive as well as negative, and long-term as well as short-term, effects on the disease and the body. Among the 21 respondents who reported instances of intentional nonadherence, 12 reported that they had deliberately modified their treatment to check for side effects, prevent potentially harmful long-term effects, or improve its effectiveness, by assessing the effects on their body, complaints, and medical data of these behavior changes. These respondents were eight men and four women: four with hypertension, four with type 2 diabetes, two with chronic myeloid leukemia, one with inflammatory bowel syndrome, and one with Parkinson's disease. Among these 12 respondents, five were 66 years old and over, five were between 50 and 65 years old, and two were between 30 and 49 years old; nine were married, one was cohabiting, and two were divorced; and $11 \mathrm{had}$ completed secondary education, and two had completed tertiary education. Compared with all 48 respondents, 
men are overrepresented in this group but it is not possible to draw conclusions from this observation.

\section{Patients' Desire to Control the Hold of the Treatment on Their Life, Their Time, and Their Activities}

To our knowledge, the second cause of nonadherence reported by the respondents had not been identified until now. Some respondents stated that their intentional nonadherence resulted from a desire to control and contain the hold of the treatment on their life, their time, and their activities. They felt that this hold was sometimes too strong for them, on a practical and on a motivational plane. On a practical plane, the respondents tried to limit or reduce the time they have to dedicate daily to health care, by removing parts of the related tasks or by adjusting them. On a motivational plane, they sometimes felt that the efforts did not match the results and searched for treatment modifications that would enable them to overcome demotivation.

Some respondents expressed that their treatment is a burden and that they sometimes feel that this burden is too heavy for them. Then, they have to remove the heaviest parts of this burden. These parts were often related to diet, physical activity, or measuring biological values themselves, and to a lesser extent, the medications. In particular, the most time-consuming treatment-related tasks may appear particularly demanding, to the extent that some respondents refused to perform these tasks. This was the case for this 69year-old man, who has had Parkinson's disease for 12 years. He explained that he rigorously complied with the medical recommendations in general, but he sometimes felt that this went beyond his capacity:

At some point, I'd had it with the exercises that I had to do at home. Because I had to exercise every day between 15 minutes to half an hour in the morning. And at some point I said: I can no longer do that. That's just too much for me. Yes, I was busy with it for the whole day. There was nothing else anymore.

A similar feeling of having to perform an impossible task was described by this 76-year-old woman, who has had type 2 diabetes for 15 years:

You know what I find annoying? The food lists. For three days, you must write down precisely what you eat. For each lick of butter, and this is really impossible for me, I have to look at the packet of butter and write down the carbohydrates and count them, for one day. Well, this list, I tend sometimes to, hmm ... throw it away.

These nonadherent behaviors are not limited to physical activities, diet, or measuring. Medication taking can also be experienced as a burdensome task. This was what this 29 -year-old man who has had inflammatory bowel disease for 4 years said,
And during the summer, I went to Vietnam with my brother, and I had to take one and a half pills per day, one pill in the morning and half a pill in the evening, and yes, in the evening, most of the time, we had had dinner, and we were sitting with a beer and then I thought: oh yes, the half pill? It did not make sense. So, for a while, I took just one pill... . It's because this half pill is not practical. So he (the doctor) said, let's simply take one pill every day, and twice in the week, two pills. So.

The amount of work the patients have to perform because of a chronic illness can thus lead them to temporarily remove or modify some tasks and result in intentional nonadherence.

But the nature of this work, and not only its quantity, also elicited such behaviors. Indeed, the respondents expressed they were sometimes downhearted about their treatment, saying, for instance, "I'd had enough" and "it does not make sense." The lack of positive perspective seems to lead patients to question being fully adherent to their treatment and sometimes to consider interrupting it.

This is what one respondent described about measuring. This 68 -year-old woman who has had type 2 diabetes for 20 years knows what the consequences of nonadherence would be, but she explained that this does not counterweigh her feeling of uselessness regarding some treatment-related tasks:

A couple of years ago, I said something like: I'm not writing my measurements any longer and ... it does not make sense. Then the doctor got angry and said: yes, you can stop that, but then you should just let us know. That was it (laughs). He did not understand. No. That this sometimes takes you by the throat, all the things you have to do, all these controls. Yes . . . I know well what the consequences would be of course, hey? Yes I mean . . . But sometimes, you don't mind, hey? There are such moments, but, well.

As previously, medication taking was not reported to be the first task affected by intentional nonadherence. However, some respondents explained that they are sometimes disheartened about it, as did this 60-year-old man who has had type 2 diabetes for 4 years:

Sometimes, I'm fed up with it. So, yes, every day, eight pills. The blood pressure and all. At some point, I'm really fed up with it. But, but . . . I simply take them, though, so $\mathrm{hm}$... [laughs]. I know . . . I'm not angry, but again and again you have to do these things. Sometimes, yes, I am fed up with it. But ... I have to keep going.

The temptation of nonadherence seems related to the fact that a daily task does not produce satisfactory or tangible results and therefore becomes disheartening. Respondents said they knew that the consequences of nonadherence would be negative and they had no choice in this respect. But these arguments are not always enough to keep them motivated. Thus, they sometimes try to cope by temporarily interrupting their treatment. This describes the situation with this 38-year-old woman 
who has had hypertension for 5 years and was prescribed a diet:

Of course [laughs]. There are many things that I am not allowed to eat (laughs). Yes, yes and then . . . That's something I was fed up with, for instance, during last summer holidays. That's something I've stopped. At some point, I'd had enough with it. I thought it simply did not make sense to me . . . to drop this and drop that ... Of course, this has consequences. This has consequences on my blood sugar values, on the cholesterol . . . Of course, this has an effect.

A similar behavior was reported by this 67-year-old man, who has had type 2 diabetes for 20 years, and who insisted that he needed to be temporarily in control over his life, in spite of the negative consequences he would experience afterwards:

At some point, you rebel; you think, now, it's enough. Now, I do for once something that I have decided myself. But after some days, there is the weighing scale and you are really punished.

This complex feeling of uselessness, weariness, and need for control over one's life thus leads to temporary nonadherence behaviors that aim to put a temporary end to an absurd-seeming task, to store up energy during this treatment break, to do enjoyable things, and to be in control again.

This type of nonadherence behavior was described by 10 respondents. Among them were six men and four women; six had type 2 diabetes, two had inflammatory bowel disease, one had hypertension, and one had Parkinson's disease. Among them, five were 66 years old and above, three were between 50 and 65 years old, one was between 30 and 49, and one was below 30 years old; seven were married and three were single; and two had completed primary education only, six had completed secondary education only, and two had completed tertiary education. Contrary to what one might have expected, type 2 diabetes and hypertension are not overrepresented, and young patients are also present in this group. However, it is not possible to draw a conclusion from these observations.

\section{Discussion and Conclusion}

This study evidenced two causes of intentional nonadherence that had not been, to our knowledge, identified previously: A desire to control the effects of the treatment, and thus to adjust the treatment through self-designed micro experiments, and a desire to control and contain the hold of the treatment on personal life, which can cause the patients to reject or modify certain treatment-related tasks or to take breaks when they are disheartened. Identifying these two types of control allows a better understanding of the temporary and fluctuating dimension of intentional nonadherence.
The FMEA method was useful to connect both objective and subjective dimensions of intentional nonadherence, that is, the concrete behavior of the interviewees and their interpretation thereof. Indeed, focusing on the instances of intentional discrepancies between prescribed and actual behavior, and not only on patients' subjective experience in general, allowed us to engage in a deeper understanding of the fluctuations of adherence behavior and the reasons for it. The results of our study are thus in line with studies that pointed to the burden of managing a chronic illness, to its different dimensions such as financial burden, time and travel burden, medication burden, health care access burden (Sav et al., 2013) or side effects, cost, time, impact on family and lifestyle (Sav et al., 2015), and to its dynamic nature (Sav et al., 2015). However, the FMEA method made it possible to understand a key underlying dimension of this burden, namely, patients' feeling that there are losing control over their own life. The results of our study are also useful to better understand patients' strategies for adaptation and coping. Those aim not only at reducing the illness burden but also at holding on to control, even if the burden could appear relatively small for external observers.

The FMEA method would be of interest for medical teams wishing to help patients improve their adherence behavior. In line with the FMEA approach, adherence can indeed be viewed as a continual quality control cycle of assessing, adapting, and maintaining behaviors. Medical teams could, for instance, precisely describe the medication adherence process and the corresponding work flow, identify all the causes for possible divergences, and then think of how health practitioners could help patients both maintaining the work flow and exercising control.

These results emerged from an analysis of adherence as an active process, a set of tasks performed by patients with a chronic disease. This perspective is rooted in now classical sociological studies on the work of the patients and their relatives, and more particularly on health care tasks performed at home for chronic illness (Corbin \& Strauss, 1988; Senteio \& Veinot, 2014). Such a perspective can be fruitfully deepened and enriched by more recent psychological research on motivation and commitment in the workplace. Indeed, some results presented here are in line with this literature. The issue of routine jobs and the fact that unenriched routine work can lead to depression has long been known in the sociology and psychology of work (Parker, 2003). The time that patients spend on their daily care is of course not equivalent to a full day of work, but the problem of routine clearly arises, as suggested by the disheartened perspective some respondents expressed about their treatment.

Another major issue in the sociology and psychology of work was also apparent in the interviews: autonomy. Job autonomy is very important for employees, and it has been evidenced that it could improve work 
performance (Cordery, 1997; Howard, 1995). Autonomy operates along three dimensions: method, timing, and goals (Spector, 1986). These dimensions are also present in the experiments reported by respondents: They chose a method for assessing the effects of their treatment on their body and biological parameters, they adjusted their time schedule, and they paid attention to the fit between their life goals and their activities, including health care activities. It is interesting to note that employees' autonomy is affected by the attitude of their superiors, and by how the supervisor (a) provides clear, attainable goals, (b) exerts control over work activities, (c) ensures that the requisite resources are available, and (d) gives timely, accurate feedback on progress toward goal attainment (Cordery, 1997). Studying how these results could be transposed to the therapeutic relationship, and how they affect treatment adherence, has the potential to improve our understanding of adherence.

Motivation in the workplace is related to autonomy but also to goal setting (Locke \& Latham, 2002). This is probably one of the major challenges for the patients. All respondents expressed that they pursued negative goals, to the extent that all they could expect was to avoid getting worse and, at best, remain in their current state. This has a negative impact on their adherence behavior because such goals are not suited to maintain motivation in the long run. They produce no tangible results and may elicit the feeling that the goals are not attainable, precisely because they are not tangible. How these types of negative goals may influence patients' motivation at work would need to be examined closely, as well as how other, more tangible, goals could be devised and pursued.

Our study was limited to a particular cultural and institutional setting, in the Netherlands. Further studies in non-European countries and targeting more specifically other types of patients and/or other types of health services would be needed to fully confirm our results.

Patients need to act in an intentionally nonadherent way to exert control over the treatment and its effects on their body and to control the hold of the treatment on their life, their time, and their activities, and they subsequently modify their adherence behavior in accordance with the impact of these actions either on their condition or their personal life. This result provides a rationale for fluctuating nonadherence behavior and opens new research and intervention perspectives on this issue.

\section{Declaration of Conflicting Interests}

The authors declared no potential conflicts of interest with respect to the research, authorship, and/or publication of this article.

\section{Funding}

The authors disclosed receipt of the following financial support for the research, authorship, and/or publication of this article: This research was supported by a Marie Curie grant of the European Commission (Marie Curie CIG 321855), by a grant from the Région Nord Pas-de-Calais and by a grant from Lille Métropole.

\section{References}

Chambers, J. A., O’Carroll, R. E., Hamilton, B., Whittaker, J., Johnston, M., Sudlow, C., \& Dennis, M. (2011). Adherence to medication in stroke survivors: A qualitative comparison of low and high adherers. British Journal of Health Psychology, 16, 592-609. doi:10.1348/2044-8287.002000

Clifford, S., Barber, N., \& Horne, R. (2008). Understanding different beliefs held by adherers, unintentional nonadherers, and intentional nonadherers: Application of the Necessity-Concerns Framework. Journal of Psychosomatic Research, 64, 4 1-46. doi:10.1016/ j.jpsychores.2007.05.004

Conrad, P. (1985). The meaning of medications: Another look at compliance. Social Science \& Medicine, 20, 29-37.

Cooper, J. K., Love, D. W., \& Raffoul, P. R. (1982). Intentional prescription nonadherence (noncompliance) by the elderly. Journal of the American Geriatrics Society, 30, 329-333.

Corbin, J. M., \& Strauss, A. L. (1988). Unending work and care: Managing chronic illness at home (1st ed.). San Francisco: Jossey-Bass.

Cordery, J. (1997). Reinventing work design theory and practice.Australian Psychologist, 32, 18 5-189. doi:10.1080/00050069708257379.

Daleboudt, G. M. N., Broadbent, E., McQueen, F., \& Kaptein, A. A. (2010). Intentional and unintentional treatment nonadherence in patients with systemic lupus erythematosus. Arthritis Care \& Research, 63, 342-350. doi:10.1002/acr.20411

de Vries, S. T., Keers, J. C., Visser, R., de Zeeuw, D., HaaijerRuskamp, F. M., Voorham, J., \& Denig, P. (2014). Medication beliefs, treatment complexity, and nonadherence to different drug classes in patients with type 2 diabetes. Journal of Psychosomatic Research, 76, 134-138. doi:10.1016/j.jpsychores.2013.11.003

DiMatteo, M. R. (2004). Variations in patients' adherence to medical recommendations: A quantitative review of 50 years of research. Medical Care, 42, 200-209. doi:10.1097/ 01.mlr.0000114908.90348.f9

Ford, E. C., Gaudette, R., Myers, L., Vanderver, B., Engineer, L., Zellars, R., . . . DeWeese, T. L. (2009). Evaluation of safety in a radiation oncology setting using failure mode and effects analysis. International Journal of Radiation Oncology * Biology * Physics, 74, 852-858. doi:10.1016/ j.ijrobp.2008.10.038

Franklin, B. D., Shebl, N. A., \& Barber, N. (2012). Failure mode and effects analysis: Too little for too much? BMJ Quality \& Safety, 21, 607-611. doi:10.1136/bmjqs-2011000723.

Herrera, P. A., Moncada, L., \& Defey, D. (2016). Understanding non-adherence from the inside: Hypertensive patients motivations for adhering and not adhering. Qualitative Health Research. Advance online publication. doi:10.1177/1049732316652529

Hertig, J. B., Hultgren, K. E., Parks, S., \& Rondinelli, R. (2016). Development and assessment of a medication safety measurement program in a long-term care pharmacy. The Consultant Pharmacist, 31, 112-118. doi:10.4140/TCP.n.2016.112

Howard, A. (Ed.). (1995). The changing nature of work (1st ed.). San Francisco: Jossey-Bass. 
Iihara, N., Nishio, T., Okura, M., Anzai, H., Kagawa, M., Houchi, H., \& Kirino, Y. (2014). Comparing patient dissatisfaction and rational judgment in intentional medication non-adherence versus unintentional nonadherence. Journal of Clinical Pharmacy and Therapeutics, 39, 45-52. doi:10.1111/jcpt.12100

Iihara, N., Tsukamoto, T., Morita, S., Miyoshi, C., Takabatake, K., \& Kurosaki, Y. (2004). Beliefs of chronically ill Japanese patients that lead to intentional non-adherence to medication. Journal of Clinical Pharmacy and Therapeutics, 29, 41 7-424. doi:10.1111/j.13652710.2004.00580.x

Khan, M., Shah, S., \& Hameed, T. (2014). Barriers to and determinants of medication adherence among hypertensive patients attended National Health Service Hospital, Sunderland. Journal of Pharmacy and Bioallied Sciences, 6, 104-108. doi:10.4103/0975-7406.129175

Laba, T.-L., Brien, J., Fransen, M., \& Jan, S. (2013). Patient preferences for adherence to treatment for osteoarthritis: The Medication Decisions in Osteoarthritis Study (MEDOS). BMC Musculoskeletal Disorders, 14(1), Article 160. doi:10.1186/1471-2474-14-160

Laba, T.-L., Brien, J., \& Jan, S. (2012). Understanding rational non-adherence to medications. A discrete choice experiment in a community sample in Australia. BMC Family Practice, 13(1), Article 61. doi:10.1186/14712296-13-61

Laba, T.-L., Lehnbom, E., Brien, J., \& Jan, S. (2015). Understanding if, how and why non-adherent decisions are made in an Australian community sample: A key to sustaining medication adherence in chronic disease? Research in Social \& Administrative Pharmacy, 11, 154-162. doi:10.1016/j.sapharm.2014.06.006

Locke, E. A., \& Latham, G. P. (2002). Building a practically useful theory of goal setting and task motivation: A 35year odyssey. American Psychologist, 57, 705-717. doi:10.1037/0003-066X.57.9.705

Lux, A., Mawo De Bikond, J., Etienne, A., \& QuillerouGrivot, E. (2016). FMEA and consideration of real work situations for safer design of production systems. International Journal of Occupational Safety and Ergonomics: JOSE, 22, 557-564. doi:10.1080/ 10803548.2016.1180856

Murdoch, J., Salter, C., Poland, F., \& Cross, J. (2015). Challenging social cognition models of adherence: Cycles of discourse, historical bodies, and interactional order. Qualitative Health Research, 25, 283-294. doi:10.1177/ 1049732314552074

Noens, L., Hensen, M., Kucmin-Bemelmans, I., Lofgren, C., Gilloteau, I., \& Vrijens, B. (2014). Measurement of adherence to BCR-ABL inhibitor therapy in chronic myeloid leukemia: Current situation and future c halle nges.Haematologica, 99, 43 7-447. doi:10.3324/haematol.2012.082511

Norton, W., Amico, K. R., Fisher, W., Shuper, P., Ferrer, R., Cornman, D., . . . Fisher, J. (2010). Informationmotivation-behavioral skills barriers associated with intentional versus unintentional ARV non-adherence behavior among HIV+ patients in clinical care. AIDS Care, 22, 979-987. doi:10.1080/09540121003758630

Ostini, R., \& Kairuz, T. (2014). Investigating the association between health literacy and non-adherence. International Journal of Clinical Pharmacy, 36,3 6-44. doi:10.1007/s11096-013-9895-4

Parker, S. K. (2003). Longitudinal effects of lean production on employee outcomes and the mediating role of work characteristics. Journal of Applied Psychology, 88, 620-634. doi:10.1037/0021-9010.88.4.620
Pound, P., Britten, N., Morgan, M., Yardley, L., Pope, C., Daker-White, G., \& Campbell, R. (2005). Resisting medicines: A synthesis of qualitative studies of medicine taking. Social Science \& Medicine, 61, 133-155. doi:10.1016/j.socscimed.2004.11.063

Sav, A., Kendall, E., McMillan, S. S., Kelly, F., Whitty, J. A., King, M. A., \& Wheeler, A. J. (2013). "You say treatment, I say hard work": Treatment burden among people with chronic illness and their carers in Australia. Health \& Social Care in the Community, 21, 665-674. doi: $10.1111 /$ hsc. 12052

Sav, A., King, M. A., Whitty, J. A., Kendall, E., McMillan, S. S., Kelly, F., . . . Wheeler, A. J. (2015). Burden of treatment for chronic illness: A concept analysis and review of the literature. Health Expectations, 18, 312-324. doi:10.1111/hex.12046

Senteio, C., \& Veinot, T. (2014). Trying to make things right: Adherence work in high-poverty, African American neighborhoods. Qualitative Health Research, 24, 1745-1756. doi:10.1177/1049732314549027

Spector, P. E. (1986). Perceived control by employees: A metaanalysis of studies concerning autonomy and participation a t work.Human Relations, 39, $1005-1016$. doi:10.1177/001872678603901104

Thunander Sundbom, L., \& Bingefors, K. (2012). Women and men report different behaviours in, and reasons for medication non-adherence: A nationwide Swedish survey. Pharmacy Practice, 10, 207-221. doi:10.4321/S188636552012000400005

Ulrik, C. S., Backer, V., Søes-Petersen, U., Lange, P., Harving, H., \& Plaschke, P. P. (2006). The patient's perspective: Adherence or non-adherence to asthma controller therapy? The Journal of Asthma: Official Journal of the Association for the Care of Asthma, 43, 701-704. doi:10.1080/ 02770900600925569

Wileman, V., Chilcot, J., Norton, S., Hughes, L., Wellsted, D., \& Farrington, K. (2011). Choosing not to take phosphate binders: The role of dialysis patients' medication beliefs. Nephron Clinical Practice, 119, 20 5-213. doi:10.1159/000329106

World Health Organization. (Ed.). (2003). Adherence to longterm therapies: Evidence for action. Geneva: Author.

Wroe, A. L. (2002). Intentional and unintentional nonadherence: A study of decision making. Journal of Behavioral Medicine, 25, 355-372.

Wroe, A., \& Thomas, M. (2003). Intentional and unintentional nonadherence in patients prescribed HAART treatment regimens. Psychology, Health \& Medicine, 8, 453-463. doi: $10.1080 / 1354850310001604595$

Zwikker, H., van den Bemt, B., Vriezekolk, J., van den Ende, C., \& van Dulmen, S. (2014). Psychosocial predictors of non-adherence to chronic medication: Systematic review of longitudinal studies. Patient Preference and Adherence, 519-563. doi:10.2147/PPA.S47290 